\title{
Pengaruh IPM dan PDRB terhadap Jumlah Penduduk Miskin di Sumatera Utara Tahun 2002-2017
}

\author{
Putri Sari M J Silaban \\ Universitas Negeri Medan \\ ellonagultom01@gmail.com
}

\section{Permata Sari Br Sembiring \\ Universitas Negeri Medan \\ intanpermatasaribrsembiring@gmail.com}

\author{
Vini Alvionita Br Sitepu \\ Universitas Negeri Medan \\ vinialvionitasitepu@gmail.com
}

\section{Jessica Putri Br.Sembiring \\ Universitas Negeri Medan \\ jessicasembiring76@gmail.com}

\begin{abstract}
Abstrak
Kemiskinan merupakan salah satu masalah terbesar yang ada di berbagai wilayah di Indonesia, salah satunya di Provinsi Sumatera Utara. Tingkat kemiskinan di Provinsi Sumatera Utara terus mengalami fluktuasi dan masalah ini setiap tahunnya menjadi sorotan serius. Masalah kemiskinan ini harus segera diatasi. Oleh karena itu, penelitian ini bertujuan untuk menganalisis seberapa besar pengaruh indikator ekonomi, dimana indikator ekonomi yang digunkana adalah Produk Domestik Bruto dan Indeks Pembangunan Manusia terhadap jumlah penduduk miskin di Sumatera Utara tahun 2002 sampai dengan 2017 baik secara simultan maupun secara parsial. Jenis data yang digunakan dalam penelitian ini adalah data sekunder time series dari tahun 2002 sampai dengan 2017. Data yang digunakan yang digunakan ialah data yang diperoleh dari website resmi Badan Pusat Statistik (BPS) Sumut. Metode analisis yang digunakan dalam penelitian ini adalah analisis regresi linier berganda dengan software statistika dan ekonometrika Eviews 9. Hasil penelitian menunjukkan bahwa Secara parsial Produk Domestik Rill Bruto (PDRB) memiliki pengaruh negatif dan signifikan terhadap jumlah penduduk miskin di Sumatera Utara pada tahun 2002 sampai dengan 2017; Secara parsial Indeks Pembangunan Manusia memiliki pengaruh negatif dan signifikan terhadap jumlah penduduk miskin di Sumatera Utara pada tahun 2002 sampai dengan 2017. Secara simultan variabel Produk Domestik Rill Bruto dan Inflasi memiliki pengaruh signifikan terhadap jumlah penduduk miskin di Sumatera Utara pada tahun 2002 sampai dengan 2017. Implikasi yang dapat diberikan dari penelitian ini adalah, IPM sebagai variabel yang paling dominan dan signifikan, maka Pemerintah Provinsi Sumatera Utara perlu untuk meningkatkan IPM masyarakatnya dengan cara memberikan dan meningkatkan fasilitas kesehatan dan pendidikan yang memadai. Sementara, dari sisi PDRB,
\end{abstract}


Pemerintah Sumatera Utara perlu melakukan Pemerataan Produk Domestik Regional Bruto (PDRB) agar merata ke setiap golongan miskin yang ada di Provinsi Sumatera Utara, melaksanakan pembangunan yang berorientasi pada pemerataan produk hasil-hasil ekonomi ke seluruh penduduk serta melakukan upaya peningkatan pertumbuhan Produk Domestik Regional Bruto (PDRB) di setiap sektor lapangan usaha dengan menggunakan potensi-potensi yang dimiliki.

Kata Kunci jumlah penduduk miskin, PDRB, IPM

\section{PENDAHULUAN}

Kemiskinan merupakan salah satu masalah yang selalu dihadapi oleh manusia. Masalah kemiskinan ini dapat melibatkan seluruh aspek kehidupan manusia, walaupun seringkali tidak disadari kehadirannya sebagai sebuah masalah. Bagi mereka yang tergolong miskin, kemiskinan merupakan sesuatu yang nyata ada dalam kehidupan sehari hari, karena mereka merasakan dan menjalani sendiri bagaimana mereka hidup dalam kemiskinan. Walau demikian belum tentu mereka sadar akan kemiskinan yang mereka jalani. Tetapi kesadaran itu akan muncul ketika mereka membandingkan kehidupan yang mereka jalani dengan kehidupan orang lain yang tergolong mempunyai tingkat kehidupan social yang lebih tinggi.

Dari kemiskinan inilah timbul berbagai macam masalah social yang komplit, lihat saja disepanjang jalanan kota maupun desa semakin banyaknya gepeng di pinggir-pinggir jalan bertebaran, PSK semakin bertambah dan semakin bertambah pula anak jalanan yang terkenan razia, bisa' dipastikan 90\%'faktor utama nya ialah kondisi ekonomi yang rendah, belum lagi soal meningkatnya jumlah anak putus sekolah yang disebabkan ketidak mampuannya untuk memenuhi kebutuhan sekolah dimana setiap tahunnya selalu saja meningkat jumlahnya yang dalam hal ini di gambarkan dengan Indeks Pembangunan Manusia (IPM), anak-anak dibawah umur sudah menjadi pengemis, hal tersebut semakin jelas bahwa kemiskinan itu benar-benar ada setiap Negara (Suliswanto, 2010).

Provinsi Sumatera Utara yang beribukotakan Medan, merupakan provinsi dengan jumlah penduduk terbesar keempat setelah Jawa Barat, Jawa Timur, dan Jawa Tengah. Dan hal ini berarti, bahwa Provinsi Sumatera Utara, merupakan provinsi dengan jumlah penduduk terbesar pertama di Pulau Sumatera. Namun, dengan jumlah penduduk yang besar ini, bukan berarti Provinsi Sumatera Utara dinobatkan menjadi provinsi yang dimana masyarakatnya sejahtera. Tercatat bahwa Provinsi Sumatera Utara berada di peringkat kelima dari sepuluh provinsi termiskin di Pulau Sumatera.Tingkat kemiskinan di Provinsi Sumatera Utara terus mengalami fluktuasi dari tahun 2002-2017.

Oleh karena itu, Pemerintah Provinsi Sumatera Utara menyadari bahwa pembangunan adalah salah satu upaya untuk mewujudkan masyarakat adil dan makmur. Sejalan dengan tujuan tersebut, berbagai kegiatan pembangunan telah diarahkan kepada pembangunan daerah-daerah yang ada di Sumatera Utara, khususnya daerah yang relative mempunyai kemiskinan yang terus naikdari tahun ke tahun. Pembangunan daerah dilakukan secara terpadu dan berkesinambungan sesuai prioritas dan kebutuhan masingmasing daerah dengan akuar dan sasaran pembangunan nasional yang telah ditetapkan melalui pembangunan jangka panjang dan jangka pendek. Oleh karena itu, salah satu indicator utama keberhasilan pembangunan suatu daerah adalah laju penurunan jumlah 
penduduk miskin. Efektivitas dalam menurunkan jumlah penduduk miskin merupakan pertumbuhan utama dalam memilih strategi atau instrument pembangunan. Hal ini berarti salah satu kriteria utama pemilihan sector titik berat atau sector andalan pembangunan nasional adalah efektivitas dalam penurunan jumlah masyarakat miskin (Simatupang \& Saktyanu, 2003).

Untuk itu, penting dilakukan analisis terkait dengan masalah kemiskinan.Untuk mengurangi angka kemiskinan di Provinsi Sumatera Utara serta mewujudkan masyarakat Sumatera Utara yang sejahtera, dengan tujuan mengetahui apa saja sebenarnya penyebab dari meningkatnya angka kemiskinan dan solusi dalam mengatasinya.

\section{LANDASAN TEORI}

\section{A. 1. Kemiskinan}

Kemiskinan merupakan kondisi dimana seseorang tidak dapat menikmati segala macam pilihan dan kesempatan dalam pemenuhan kebutuhan dasarnya, seperti tidak dapat memenuhi kesehatan, standar hidup layak, kebebasan, harga diri, dan rasa dihormati seperti orang lain, serta suramnya masa depan bangsa dan negara. Kemiskinan merupakan masalah yang dihadapi oleh seluruh negara, terutama di negara berkembang seperti Indonesia. Hal ini dikarenakan kemiskinan bersifat multidimensional, artinya karena kebutuhan manusia itu bermacam-macam, maka kemiskinan pun memiliki banyak aspek primer yang berupa miskin akan aset, organisasi sosial politik, pengetahuan, dan keterampilan serta aspek sekunder yang berupa miskin akan jaringan sosial, sumbersumber keuangan, dan informasi (Indra, 2013)

Menurut Djojohadikusumo 1995, pola kemiskinan ada empat yaitu, persistent poverty, cyclical poverty, seasonal poverty, dan accidental poverty. Secara ekonomi, kemiskinan dapat dilihat dari tingkat kekurangan sumber daya yang dapat digunakan dalam memenuhi kebutuhan hidup serta meningkatkan kesejahteraan sekelompok orang. Secara politik, kemiskinan dapat dilihat dari tingkat akses terhadap kekuasaan yang mempunyai pengertian tentang sistem politik yang dapat menentukan kemampuan sekelompok orang dalam menjangkau dan menggunakan sumber daya. Secara sosial, kemiskinan dapat dilihat dari tingkat kekurangan informasi dan struktur sosial yang mendukung dalam mendapatkan kesempatan peningkatan produktivitas.

Ukuran kemiskinan menurut Nurkse (1953) dalam Kuncoro, (1997) secara sederhana dan yang umum digunakan dapat dibedakan menjadi tiga, yaitu: Kemiskinan Absolut, Relatif dan Kultural. Menurut Paul Spicker, penyebab kemiskinan dibagi menjadi empat mahzab, yaitu Individual explanation, Familial explanation, Subcultural explanation, dan Structural explanation.

Penyebab Kemiskinan dari sisi ekonomi menurut Sharp (dalam Sukmaraga P. 2011) adalah:

1. Secara mikro, kemiskinan muncul karena adanya ketidaksamaan pola kepemilikan sumberdaya yang menimbulkan distribusi pendapatan yang timpang. Penduduk miskin hanya memiliki sumberdaya dalam jumlah terbatas dan kualitasnya rendah.

2. Kemiskinan muncul akibat perbedaan dalam kualitas sumberdaya manusia. Kualitas sumberdaya manusia yang rendah berarti produktivitasnya rendah, yang pada gilirannya upahnya rendah. Rendahnya kualitas sumberdaya manusia ini karena rendahnya pendidikan, nasib yang kurang beruntung, adanya diskriminasi, atau karena keturunan.

3. Kemiskinan muncul akibat perbedaan akses dalam modal.

\section{Indeks Pembangunan Manusia (IPM)}


Syaifullah A. \& Malik N. (2017) Indeks Pembangunan Manusia (IPM) merupakan indeks komposit yang dihitung sebagai rata-rata-sederhana dari tiga indeks yang menggambarkan kemampuan dasar manusia dalam memperluas pilihan-pilihan, yaitu: Indeks Harapan Hidup, Indeks Pendidikan, dan Indeks Standar Hidup Layak

Rumus umum yang dipakai adalah sebaga berikut:

$\mathrm{IPM}=1 / 3(\mathrm{X} 1+\mathrm{X} 2+\mathrm{X} 3)$

Keterangan :

X1 = Indeks Harapan Hidup

$\mathrm{X} 2$ = Indeks Pendidikan

X3 = Indek standar Hidup Layak

Menurut Badan Pusat Statistik (2007) dalam Sukmaraga P. 2011, Indeks pembangunan manusia (IPM) merupakan ukuran capaian pembangunan manusia berbasis sejumlah komponen dasar kualitas hidup. IPM menggambarkan beberapa komponen, yaitu capaian umur panjang dan sehat yang mewakili bidang kesehatan; angka melek huruf, partisipasi sekolah dan rata-rata lamanya bersekolah mengukur kinerja pembangunan bidang pendidikan; dan kemampuan daya beli masyarakat terhadap sejumlah kebutuhan pokok. Penghitungan IPM sebagai indikator pembangunan manusia memiliki tujuan penting, diantaranya:

1. Membangun indikator yang mengukur dimensi dasar pembangunan manusia dan perluasan kebebasan memilih;

2. Memanfaatkan sejumlah indikator untuk menjaga ukuran tersebut sederhana;

3. Membentuk satu indeks komposit dari pada menggunakan sejumlah indeks dasar;

4. Menciptakan suatu ukuran yang mencakup aspek sosial dan ekonomi. Indeks tersebut merupakan indeks dasar yang tersusun dari dimensi berikut ini :

a. Umur panjang dan kehidupan yang sehat, dengan indikator angka harapan hidup;

b. Pengetahuan, yang diukur dengan angka melek huruf dan kombinasi dari angka partisipasi sekolah untuk tingkat dasar, menengah dan tinggi; dan

c. Standar hidup yang layak, dengan indikator PDRB per kapita dalam bentuk Purchasing Power Parity (PPP).

Konsep Pembangunan Manusia yang dikembangkan oleh Perserikatan Bangsa-Bangsa (PBB), menetapkan peringkat kinerja pembangunan manusia pada

skala $0,0-100,0$ dengan katagori sebagai berikut :

a. Tinggi : IPM lebih dari 80,0

b. Menengah Atas : IPM antara 66,0-79,9

c. Menengah Bawah : IPM antara 50,0 - 65,9

d. Rendah : IPM kurang dari 50,0

3. Produk Domestik Regional Bruto (PDRB)

Produk Domestik Regional Bruto (PDRB) adalah indikator ekonomi makro yang dapat memberikan gambaran tentang keadaan perekonomian suatu wilayah. Di dalam menghitung Produk Domestik Regional Bruto (PDRB) yang di timbulkan dari suatu region, ada 3 pendekatan yang digunakan yaitu:

1. $\quad$ PDRB menurut pendekatan produksi Merupakan jumlah nilai barang atau jasa akhir yang dihasilkan oleh berbagai unit produksi yang berada di suatu wilayah dalam jangka waktu tertentu;

2. PDRB menurut pendekatan pendapatan Merupakan balas jasa yang digunakan oleh faktor-faktor produksi yang ikut serta dalam proses produksi di suatu wilayah dalam waktu tertentu; 
3. PDRB menurut pendekatan pengeluaran Merupakan semua komponen pengeluaran akhir seperti: pengeluaran konsumsi rumah tangga dan lembaga swasta nirlaba, konsumsi pemerintah, pembentukan modal tetap bruto, perubahan stok dan ekspor neto dalam jangka waktu tertentu. (Prishardoyo. 2008)

\section{Teori Basis Ekonomi (Economic Base Theory)}

Teori basis ekonomi ini dikemukakan oleh Harry W. Richardson yang menyatakan bahwa faktor penentu utama pertumbuhan ekonomi suatu daerah adalah berhubungan langsung dengan permintaan akan barang dan jasa dari luar daerah.

Dalam teori basis ekonomi (economic base) bahwa semua wilayah merupakan sebuah sistem sosio ekonomi yang terpadu. Teori inilah yang mendasari pemikiran teknik location quotient, yaitu teknik yang membantu dalam menentukan kapasitas ekspor perekonomian daerah dan derajat keswasembada (Self-sufficiency) suatu sektor.

Menurut Glasson, konsep dasar basis ekonomi membagi perekonomian menjadi dua sektor yaitu:

a. Sektor-sektor basis adalah sektor-sektor yang mengekspor barang-barang dan jasa ke tempat di luar batas perekonomian masyarakat yang bersangkutan.

b. $\quad$ Sektor-sektor bukan basis adalah sektor-sektor yang menjadikan barang-barang yang dibutuhkan oleh orang yang bertempat tinggal di dalam batas perekonomian masyarakat bersangkutan. (Prishardoyo. 2008).

\section{METODOLOGI PENELITIAN}

Data Penelitian ini merupakan data sekunder perhitungan tahunan (yearly) dari tahun 2002 - 2017, jenis data yang digunakan dalam analisis ini yaitu data berskala (time series data).Indikator-indikator ekonomi yang mempengaruhi jumlah penduduk miskin antara lain, pertumbuhan ekonomi negara yang bersangkutan termasuk PDRB, tingkat investasi,pengangguran, IPM dan beberapa faktor lain. Namun dalam penelitian ini indikator yang dipakai dibatasi. Dimana indikator ekonomi yang dipakai ialah, Produk Domestik Bruto (PDRB) dan Indeks Pembangunan Manusia (IPM) saja.

Populasi yang digunakan adalah data - data yang ada di Sumatera Utara , meliputi IPM, PDRB, dan kemiskinan periode 2002 - 2017. Data yang digunakan untuk mencapai tujuan dalam penelitian ini sepenuhnya diperoleh melalui Badan Pusat Statistic Sumatera Utara dalam bentuk SUDA (Sumatera Utara Dalam Angka) serta bentuk-bentuk lain yang dikeluarkan oleh BPS Sumut periode 2002 - 2017 yang di akses melalui internet.

Dalam penelitian ini menggunakan analisis kuantitatif yaitu merupakan analisis yang menggunakan alat perhitungan statistik. Untuk mengetahui hubungan antar variabel penelitian ini menggunakan alat regresi linear berganda. Regresi linier berganda digunakan untuk menganalisis hubungan antar variabel terikat dengan variabel bebas. Dalam pengelolaan data digunakan software dalam komputer yaitu berupa Eviews 9 . Secara sistematis dirumuskan sebagai berikut:

Pengangguran $=\mathrm{C}+\beta 1 \mathrm{IPM}+\beta 2 \mathrm{PDRB}$.

Data yang digunakan untuk mencapai tujuan dalam penelitian ini sepenuhnya diperoleh melalui Badan Pusat Statistic Sumatera Utara dalam bentuk SUDA (Sumatera Utara Dalam Angka) serta bentuk-bentuk lain yang dikeluarkan oleh BPS Sumut periode 2002 - 2017 yang di akses melalui internet.

\section{HASIL PENELITIAN}

\subsection{Model Regresi Linier Berganda}


Hasil analisis regresi linier berganda untuk menguji pengaruh IPM dan PDRB terhadap Jumlah Penduduk Miskin di Sumatera Utara Tahun 2002 - 2017, disajikan pada tabel berikut:

Tabel 1

Hasil Uji Regresi Berganda

\begin{tabular}{|c|c|c|c|c|}
\hline \multicolumn{5}{|c|}{ Dependent Variable: Y } \\
\hline \multicolumn{5}{|c|}{ Method: Least Squares } \\
\hline Variable & Coefficient & Std. Error & t-Statistic & Prob. \\
\hline C & 1914852, & 50906,49 & 37,61507 & 0.0000 \\
\hline X1 & $-26,67604$ & 9,892413 & $-2,696616$ & 0.0183 \\
\hline X2 & $-0,872598$ & 0,132587 & $-6,581319$ & 0.0000 \\
\hline
\end{tabular}

Berdasarkan Tabel 1 terdapat dua variabel bebas yaitu variabel IPM dan PDRB sehingga diperoleh persamaan regresi linier berganda sebagai

berikut:

$\mathrm{Y}=1914852,-26,67604 \mathrm{X} 1-0,872598 \mathrm{X} 2$

Persamaan regresi tersebut dapat dijelaskan sebagai berikut :

1. Nilai konstanta (a) sebesar 2,677066, artinya jika IPM(X1) dan PDRB (X2) nilainya adalah 0 , maka nilai kemiskinan (Y) adalah 1914852, ;

2. Nilai koefisien regresi variabel IPM (X1) sebesar - 26,67604, artinya jika variabel bebas lain nilainya tetap dan IPM mengalami kenaikan 1 persen, maka kemiskinan (Y) akan mengalami penurunan sebesar 26,67604 jiwa dengan asumsi variabel bebas lainnya memiliki nilai tetap. Koefisien bernilai negatif artinya terjadi hubungan negatif antara IPM dengan kemiskinan, semakin tinggi nilai IPM maka semakin rendah tingkat kemiskinan di sumatera utara;

3. Nilai koefisien regresi variabel PDRB (X2) sebesar - 0,872598, yang artinya bahwa setiap penambahan 1 rupiah PDRB maka akan menurunkan tingkat kemiskinan sebesar 0,872598 jiwa dengan asumsi bahwa variabel bebas lain memiliki nilai tetap. Koefisien bernilai negatif artinya terjadi hubungan negative antara PDRB dengan ingkat kemiskinan, semakin tinggi nilai dari PDRB maka semakin rendah jumlah orang miskin di provinsi sumatera utara.

Uji Asumsi Klasik

Uji Normalitas

Tabel 2 


\section{Histogram/ Normality Test}

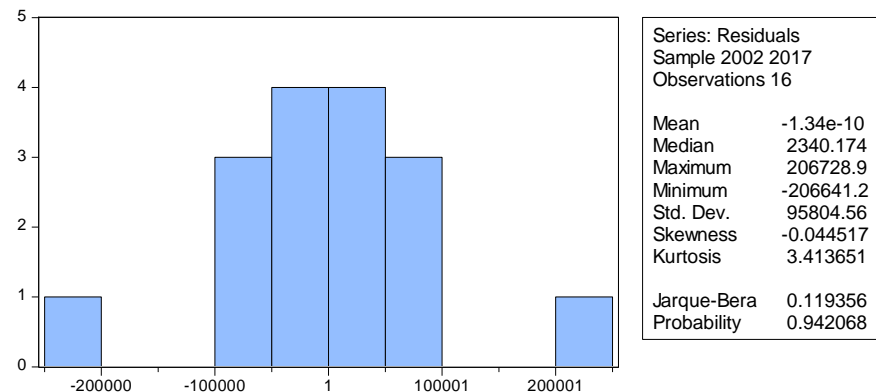

Berdasarkan Tabel 2 diatas diketahui bahwa nilai probability 0,942068>0,05 yang artinya bahwa data pada penelitian ini berdistribusi normal.

\section{Uji Autokorelasi}

Tabel 3

\begin{tabular}{|c|c|}
\hline \multicolumn{2}{|c|}{ Dependent Variable: Y } \\
\hline \multicolumn{3}{|c|}{ Method: Least Squares } \\
\hline Durbin-Watson stat & 1.626642 \\
\hline
\end{tabular}

Berdasarkan output eviews diperoleh nilai Dw seperti pada Tabel 3 diatas, nilai Dw tersebut berada diantara 1.54 dan 2.46 yaitu 1.626642 yang memiliki arti bahwa data pada penelitian ini tidak memiliki masalah autokorelasi.

Uji Multikolinearitas Tabel 4

\begin{tabular}{llll}
\hline \hline Variable & $\begin{array}{l}\text { Coefficient } \\
\text { Variance }\end{array}$ & $\begin{array}{l}\text { Uncentered } \\
\text { VIF }\end{array}$ & $\begin{array}{l}\text { Centered } \\
\text { VIF }\end{array}$ \\
\hline \hline $\mathrm{C}$ & $2.59 \mathrm{E}+09$ & 3.915129 & NA \\
$\mathrm{X} 1$ & 97.85984 & 1.259539 & 1.001479 \\
$\mathrm{X} 2$ & 0.017579 & 3.722969 & 1.001479 \\
\hline \hline
\end{tabular}

Berdasarkan Tabel 4 diatas dapat kita lihat bahwa nilai VIF dari variabel bebas penelitian ini $<10$ yang artinya tidak ada masalah multikolinearitas pada data ini.

Uji Regresi

Uji koefisien Determinasi R2

Tabel 5

Hasil Uji koefisien Determinasi

Dependent Variable: Y

Method: Least Squares 


\begin{tabular}{|c|c|}
\hline R-squared & 0.800082 \\
\hline Adjusted R-squared & 0.769325 \\
\hline
\end{tabular}

Berdasarkan tabel 5 diatas diperoleh nilai R-squared sebesar 0.800082 yang artinya bahwa variabel IPM dan PDRB mampu mempengaruhi kemiskinan di provinsi Sumatera Utara pada tahun 2002- 2017 sebesar 80,0082 \% dan sisanya sebesar 19,9918\% dipengaruhi oleh faktor lain yang tidak diteliti pada penelitian ini contohnya pengangguran, pendapatan dan adanya faktor kemalasan dari masyarakat iitu sendiri.

\section{Uji F \\ Tabel 6 \\ Hasil Uji F}

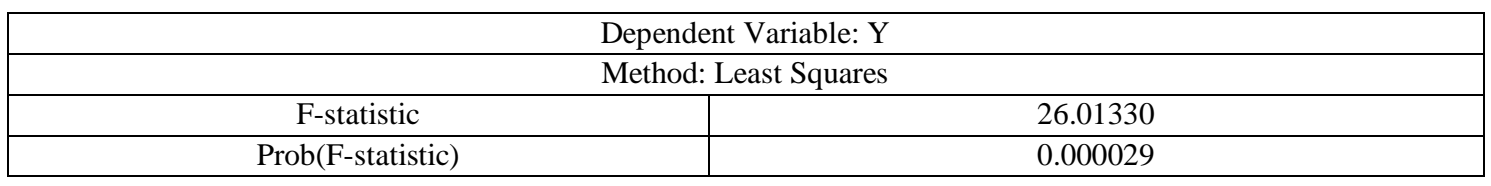

Berdasarkan hasil olah data diperoleh nilai Prob (F-statistic) seperti pada Tabel 6 diatas yaitu sebesar $0.000039<0,05$ yang artinya secara simultan variable IPM dan PDRB berpengaruh signifikan terhadap pengangguran di Sumatera Utara pada tahun 20022017.

Hal ini sejalan dengan penelitian yang dilakukan oleh Watil E. dan Sadjiarto A. (2019) yang berjudul. Pengaruh Indeks Pembangunan Manusia Dan Produk Domestik Regional Bruto Terhadap Kemiskinan yang menyatakan bahwa Terdapat pengaruh yang signifikan secara bersama-sama antara indeks pembangunan manusia dan produk domestik regional bruto terhadap kemiskinan di 35 kabupaten/kota Provinsi Jawa Tengah tahun 2012-2016 sebesar 0.451 atau 45.1 persen.

Selain itu, penelitian ini juga sejalan dengan penelitian yang dilakukan oleh Suliswanto M. S. W. (2010) dengan judul artikelnya Pengaruh Produk Domestik Bruto (PDB) dan Indeks Pembangunan Manusia (IPM) Terhadap Angka Kemiskinan di Indonesia menunjukkan hasil bahwa Secara simultan nilai F hitung sebesar 136,47 dan $\mathrm{f}$ tabel 4,00 sehingga pada penelitian ini menunjukkan bahwa PDRB dan IPM memiliki pengaruh yang signifikan terhadap kemiskinan di Indonesia.

\section{Uji t}

Tabel 7

\section{Hasil Uji t}

\begin{tabular}{|c|c|c|c|c|}
\hline \multicolumn{5}{|c|}{ Dependent Variable: Y } \\
\hline \multicolumn{5}{|c|}{ Method: Least Squares } \\
\hline Variable & Coefficient & Std. Error & t-Statistic & Prob. \\
\hline C & 1914852, & 50906,49 & 37,61507 & 0.0000 \\
\hline X1 & $-26,67604$ & 9,892413 & $-2,696616$ & 0.0183 \\
\hline X2 & $-0,872598$ & 0,132587 & $-6,581319$ & 0.0000 \\
\hline
\end{tabular}

Hasil pengolahan data diatas dapat disimpulkan sebagai berikut:
1. IPM dan Kemiskinan 
Secara parsial variabel X1(IPM) berpengaruh negatif dan signifikan terhadap kemiskinan di Sumatera Utara pada tahun 2002- 2017 dengan nilai prob sebesar 0,0183<0,05.

Hasil penelitian yang diperoleh ini sesuai dengan penelitian yang dilakukan oleh Prasetyoningrum A. K. dan Sukmawati U. S. (2018) dengan judul Analisis Pengaruh Indeks Pembangunan Manusia (IPM), Pertumbuhan Ekonomi dan Pengagguran Terhadap Kemiskinan di Indonesia menunjukkan bahwa IPM berpengaruh secara langsung dan negatif terhadap tingkat kemiskinan dengan nilai koefisien jalur -0.71.

Selain itu penelitian ini juga sejalan dengana penelitian Sukmaraga P. (2011) dengan judul penelitiannya adalah Analisis Pengaruh Indeks Pembangunan Manusia, PDRB Per Kapita, Dan Jumlah Pengangguran Terhadap Jumlah Penduduk Miskin Di Provinsi Jawa Tengah dengan hasil penelitiannya bahwa variabel Indeks Pembangunan Manusia (IPM) berpengaruh negatif dan signifikan terhadap jumlah penduduk miskin di Provinsi Jawa Tengah.

2. PDRB dan Kemiskinan

Secara parsial variabel X2 (PDRB) berpengaruh negatif dan signifikan terhadap Kemiskinan di Sumatera Utara pada tahun 2002- 2017 dengan nilai prob sebesar 0,0000 $>$ 0,05. Syaifullah A. \& Malik N. (2017) dengan judul penelitian Pengaruh Indeks Pembangunan Manusia Dan Produk Domestik Bruto Terhadap Tingkat Kemiskinan di ASEAN-4 dengan hasil penelitiannya Produk Domestik Bruto (PDB) memiliki pengaruh negatif dan signifikan terhadap tingkat kemiskinan di ASEAN-4 dengan nilai probabilitas 0,0000. Dama H. Y., Lapian A. L. Ch. dan Sumual J. I. (2016) dengan judul penelitian Pengaruh Produk Domestik Regional Bruto (PDRB) Terhadap Tingkat Kemiskinan Di Kota Manado (Tahun 2005-2014) dengan hasil penelitian bahwa Produk Domestik Regional Bruto (PDRB) berpengaruh negatif dan signifikan terhadap tingkat kemiskinan di Kota Manado.

\section{KESIMPULAN}

Dari hasil penelitian diatas penulis menarik kesimpulan bahwa:

1. Secara parsial Indeks Pembangunan Manusia memiliki pengaruh negatif dan signifikan terhadap jumlah penduduk miskin di Sumatera Utara pada tahun 20022017

2. Secara parsial Produk Domestik Rill Bruto memiliki pengaruh negatif dan signifikan terhadap jumlah penduduk miskin di Sumatera Utara pada tahun 200220017;

3. Secara simultan variabel Produk Domestik Rill Bruto dan Indeks Pembangunan Manusia memiliki pengaruh signifikan terhadap jumlah penduduk miskin di Sumatera Utara pada tahun 2003-2013;

4. Hasil penelitian ini menunjukkan bahwa variabel yang signifikan dan paling dominan terhadap jumlah penduduk miskin di Sumatera Utara pada tahun 20022017 adalah IPM.

5. Implikasi yang dapat diberikan dari penelitian ini adalah, IPM sebagai variabel yang paling dominan dan signifikan, maka Pemerintah Provinsi Sumatera Utara perlu untuk meningkatkan IPM masyarakatnya dengan cara memberikan dan meningkatkan fasilitas kesehatan dan pendidikan yang memadai. Sementara, dari sisi PDRB, Pemerintah Sumatera Utara perlu melakukan Pemerataan Produk Domestik Regional Bruto (PDRB) agar merata ke setiap golongan miskin yang ada di Provinsi Sumatera Utara, melaksanakan pembangunan yang berorientasi pada pemerataan produk hasil-hasil ekonomi ke seluruh penduduk serta 
melakukan upaya peningkatan pertumbuhan Produk Domestik Regional Bruto (PDRB) di setiap sektor lapangan usaha dengan menggunakan potensi-potensi yang dimiliki.

6. Indikator-indikator ekonomi yang mempengaruhi jumlah penduduk miskin antara lain, pertumbuhan ekonomi negara yang bersangkutan termasuk PDRB, tingkat investasi,pengangguran, IPM dan beberapa faktor lain. Namun dalam penelitian ini indikator yang dipakai dibatasi. Dimana indikator ekonomi yang dipakai ialah, Produk Domestik Bruto (PDRB) dan Indeks Pembangunan Manusia (IPM) saja.

\section{UCAPAN TERIMA KASIH}

Ucapan terima kasih diucapkan kepada semua pihak yang telah membantu penelitian ini, yang telah membantu peneliti dalam menganalisis Pengaruh IPM dan PDRB terhadap Jumlah Penduduk Miskin di Sumatera Utara Tahun 2002-2017, terutama bagi pihak yang telah menyediakan data untuk peneliti olah.

\section{DAFTAR PUSTAKA}

Dama H. Y., Lapian A. L. Ch. dan Sumual J. I. (2016) . Pengaruh Produk Domestik Regional Bruto (PDRB) Terhadap Tingkat Kemiskinan Di Kota Manado (Tahun 20052014). Jurnal Berkala Ilmiah Efisiensi, 16 (03).

Djojohadikusumo, Sumitro.(1995). Perkembangan Pemikiran Ekonomi Dasar Teori Pertumbuhan dan Ekonomi Pembangunan, Jakarta : Penerbit LP3ES

Indra, Van Wiguna.(2013). Analisis Pengaruh Pdrb, Pendidikan Dan Pengangguran Terhadap Kemiskinan Di Provinsi Jawa Tengah Tahun 2005-2010. Jurnal Ilmiah Mahasiswa FEB, 1(2).

Kuncoro, Mudrajad.(1997). Ekonomi Pembangunan, Teori, Masalah, dan Kebijakan, Edisi Ketiga, Yogyakarta: Penerbit UPP AMP YKPN.

Pombura Y.(2014). Analisis Pengaruh Produk Domestik Regional Bruto, Jumlah Penduduk Dan Jumlah Pengangguran Terbuka Terhadap Jumlah Penduduk Miskin. Skripsi. Program Studi Ekonomi Pembangunan, Universitas Negeri Papua Manokwari. DOI: 10.13140/RG.2.2.21806.20809.

Prasetyoningrum A. K. dan Sukmawati U. S.(2018). Analisis Pengaruh Indeks Pembangunan Manusia (IPM), Pertumbuhan Ekonomi dan Pengagguran Terhadap Kemiskinan di Indonesia. EQUILIBRIUM: Jurnal Ekonomi Syariah , 6( 2), 217 - 240.

Prishardoyo, Bambang .(2008). Analisis Tingkat Pertumbuhan Ekonomi Dan Potensi Ekonomi Terhadap Produk Domestik Regional Bruto (PDRB) Kabupaten Pati Tahun 2000-2005. JEJAK, 1(1),1-9.

Simatupang, Pantjar \& Saktyanu K. Dermoredjo.(2003) . Produksi Domestik Bruto, Harga dan Kemiskinan. Ekonomi dan Keuangan Indonesia,51(3),291-324. 
Sukmaraga P. (2011) . Analisis Pengaruh Indeks Pembangunan Manusia, PDRB Per Kapita, Dan Jumlah Pengangguran Terhadap Jumlah Penduduk Miskin Di Provinsi Jawa Tengah. Skripsi. Program Sarjana Fakultas Ekonomi Universitas Diponegoro

Suliswanto, M. S. W. (2010) . Pengaruh Produk Domestik Bruto (PDB) dan Indeks Pembangunan Manusia (IPM). Jurnal Ekonomi Pembangunan, 8 (2), 357- 366.

Syaifullah, \& Malik N.(2017). Pengaruh Indeks Pembangunan Manusia Dan Produk Domestik Bruto Terhadap Tingkat Kemiskinan Di Asean-4. Jurnal Ilmu Ekonomi, 1(1),107-119.

Watil E. dan Sadjiarto A.( 2019). Pengaruh Indeks Pembangunan Manusia Dan Produk Domestik Regional Bruto Terhadap Kemiskinan. Jurnal Ecodunamika, 2 (1).

Wirawan I. M. T. dan Arka S. (2015). Analisis Pengaruh Pendidikan, PDRB Per Kapita dan Tingkat Pengangguran Terhadap Jumlah Penduduk Miskin Provinsi Bali. E-Jurnal EP Unud, 4 (5), 546-560. 